\title{
Malignant Uvula Neoplasm
}

National Cancer Institute

\section{Source}

National Cancer Institute. Malignant Uvula Neoplasm. NCI Thesaurus. Code C35177.

A primary or metastatic malignant neoplasm that affects the uvula. 